\title{
Social Determinants of Disease: HIV and COVID-19 Experiences
}

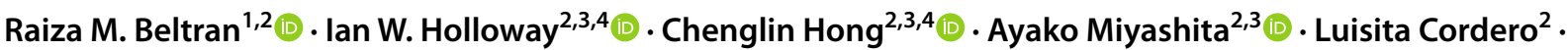 \\ Elizabeth $\mathrm{Wu}^{2,3,4} \cdot$ Katherine Burris ${ }^{5} \cdot$ Paula M. Frew ${ }^{5}$
}

Accepted: 8 November 2021 / Published online: 2 February 2022

(c) The Author(s) 2022

\begin{abstract}
Purpose of Review The differential impact of the COVID-19 and HIV pandemics on marginalized communities has renewed calls for more robust and deeper investigation into structural and social causes of health inequities contributing to these infections, including underlying factors related to systematic racism. Using the Social Determinants of Health (SDOH) framework, we analyzed parallel and divergent factors associated with COVID-19 and HIV/AIDS and the prevalence of disparate disease in diverse communities. We utilized PRISMA guidelines to identify relevant literature $(\mathrm{N}=210$ articles $)$ that resulted in a review of 125 articles included in our synthesis.

Recent Findings With racial health inequities as a core contributor to disease vulnerability, we also identified other factors such as economic stability, social and community support, the neighborhood and built environment, healthcare access and quality, and education access and quality as important socioecological considerations toward achieving health equity. Our review identifies structural and systematic factors that drive HIV and COVID-19 transmission.

Summary Our review highlights the importance of not solely focusing on biomedical interventions as solutions to ending HIV and COVID-19, but rather call for building a more just public health and social service safety net that meets the needs of people at the intersection of multiple vulnerabilities.
\end{abstract}

Keywords HIV/AIDS · COVID-19 $\cdot$ Social determinants of health $\cdot$ Racial/ethnic minorities $\cdot$ Health disparities $\cdot$ Health equity $\cdot$ Structural racism

Paula M. Frew Present address: Merck \& Co., Inc., Kenilworth, NJ, USA: Current affiliation: Merck \& Co., affiliated with UNLV when work was conducted.

This article is part of the Topical Collection on The Global Epidemic

Raiza M. Beltran

rmbeltran@mednet.ucla.edu

1 David Geffen School of Medicine, Department of Infectious Diseases, UCLA Global HIV Prevention Research Program, 10833 Le Conte Avenue, Los Angeles, CA 90095, USA

2 UCLA Hub for Health Intervention, Policy and Practice (HHIPP), CA, Los Angeles, USA

3 Department of Social Welfare, School of Public Affairs, UCLA Luskin, Los Angeles, CA, USA

4 California HIV/AIDS Research Program, Los Angeles, CA, USA

5 UNLV School of Public Health, UNLV Population Health \& Health Equity Initiative, University of Nevada, Las Vegas, NV, USA

\section{Introduction}

The differential impact of the COVID-19 and HIV pandemics on marginalized communities in the USA raised serious concerns among public health practitioners $[1 \bullet \bullet, 2 \bullet \bullet$, $3,4 \bullet \bullet]$. New data reveal the extent of rapid transmission of COVID-19 among US residents identifying as Black/African American [5, 6••], Hispanic/Latino [7, 8], Indigenous/ Native American [9•] as well as those who live in densely concentrated, low-income neighborhoods $[10 \bullet, 11 \bullet]$, and work in essential services $[12,13]$. This has renewed calls for more robust and deeper investigation to disentangle the structural and social causes of health inequities, including systematic racism $[1 \bullet \bullet, 4 \bullet \bullet, 14 \bullet \bullet, 15]$. In an effort to answer this call, and in following the CDC's recent declaration of structural racism as a serious public health threat [16], we used the CDC's Social Determinants of Health (SDOH) framework defined as "conditions in the places where people live, learn, work," to better understand how the marginalization of certain communities can leave them vulnerable to both COVID-19 and HIV (See Fig. 1, Table 1). 
Fig. 1 PRISMA Flow Diagram

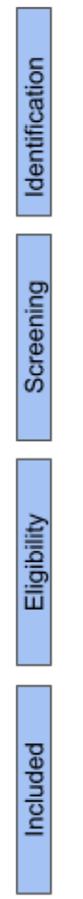

Search terms in PubMed:

((HIVIAIDS) AND (social determinants of health)) OR (disparities); (((COVID-19 OR SARS-CoV-2 OR Severe acute respiratory syndrome coronavirus 2 OR 2019 nCoV OR HCoV-19)) AND (social determinants of health)) OR (disparities)

Manual keywords search:

African Americans; Coronavirus; Coronavirus infections; Covid-19

Disparities: Ethnic groups: Health disparities Health equity: Healthcare; disparities; Hispanics; Minority groups: Pandemics People of color; Quality of care; Race/ethnicity: Racial disparities: Sars-Cov-2; Social determinants of health; Socioeconomic factors; United States

\section{Search Strategy}

Adapting PRISMA guidelines, we conducted a literature search on PubMed for publications and used a combination of keywords, phrases, and Medical Subject Headings (MeSH) that included HIV/AIDS, social determinants of health, disparities, and COVID-19 [17]. We also did a manual search for other relevant studies. We executed the initial search in October 2020 and updated the search in March 2021, which altogether yielded 286 articles. Three authors (RB, CH, LC) independently screened the titles and abstracts to narrow down eligible articles to 199 for full text review. The included articles provided empirical and original data and were published in the past 10 years and in English. Selected articles with qualitative data provided relevant context and supportive evidence. See Fig. 1 for an outline of search strategy and study selection. It is important to note that this is a limited review highlighting the features that stand out in the landscape of recent research useful for comparing COVID-19 and HIV. A broader review of published articles from multiple databases would provide a more comprehensive perspective (Fig. 2).

\section{COVID-19 and HIV-Related Health Inequities: Examining Race}

\section{COVID-19 and Racial Health Inequities}

Medical sociologists Phelan and Link [18] described racism as a "fundamental cause of health inequality" that can lead to persistent and differentiated health outcomes among racial and ethnic groups, independent of their socioeconomic status. Recent research findings on COVID-19 and HIV, substantiate Phelan and Link's assertion [18]. For COVID-19-related cases [19-23], hospitalizations [7, 24-26], and deaths [27-30], communities of color had higher rates than their white counterparts. One such study assessed ten major US cities that experienced COVID-19 surges and found that counties with more poverty and a substantial non-white population had a COVID-19 incident infection rate at 8 times higher and death rate at 9 times greater than similar counties with a substantial white population [11•]. More specifically, Black Americans, who account for only $13 \%$ of the total US population, carry a greater COVID-19-related burden in positive cases [5, 31-33]. A hospital-based study in Milwaukee found positivity rates of up to $59 \%$ among Black Americans [34]. As for hospitalization [8, 34, 35], a California-based study found that they had 2.7 times higher odds of being hospitalized than their White counterparts [8]. Additionally, 
Table 1 Conditions in the places where people live, learn, work

\begin{tabular}{|c|c|c|}
\hline COVID-19 & Racial determinants Specific factors & HIV \\
\hline$[4 \bullet \bullet, 5,8,31-36,41]$ & Black Americans: cases, hospitalizations, deaths & \\
\hline \multirow[t]{5}{*}[7,12,19,37,38,53,60\bullet]{} & Hispanic/Latino Americans: cases, hospitalizations, deaths & \\
\hline & $\begin{array}{l}\text { Black and Hispanic/Latino gay, bisexual and other men who } \\
\text { have sex with men (GBMSM): incidence, prevention and } \\
\text { treatment }\end{array}$ & {$[14 \bullet \bullet, 42,46,47,50]$} \\
\hline & $\begin{array}{l}\text { Black and Hispanic/Latino heterosexual women: incidence, } \\
\text { prevention and treatment }\end{array}$ & {$[43,44,46,48,49,51]$} \\
\hline & CDC social determinants of health Specific factors & HIV \\
\hline & Economic stability: income inequities and employment & \\
\hline$[1 \bullet \bullet, 4 \bullet \bullet, 9 \bullet, 11 \bullet, 12,15,22,25,52,53]$ & Economically disadvantaged/poverty & $\begin{array}{l}{[1 \bullet \bullet, 4 \bullet \bullet, 15,45,60 \bullet, 61-64,65 \bullet} \\
\quad 66-74]\end{array}$ \\
\hline \multirow[t]{2}{*}[1\bullet\bullet,12,13,23,33,54-59]{} & Employment instability \& work related outcomes & {$[75,76]$} \\
\hline & $\begin{array}{l}\text { Neighborhoods and built environment: housing and popula- } \\
\text { tion density }\end{array}$ & \\
\hline $\begin{array}{l}{[7,10 \bullet, 11 \bullet, 12,23,39,52,58,77,78} \\
\quad 80-84]\end{array}$ & Housing density, displacement \& instability & {$[72,77,85-87]$} \\
\hline \multirow[t]{2}{*}[23,58,79,80]{} & Population and residential density & {$[61]$} \\
\hline & $\begin{array}{l}\text { Social and community support: stigma, discrimination, } \\
\text { norms and social networks }\end{array}$ & \\
\hline$[2 \bullet \bullet, 14 \bullet \bullet, 88,90,91,92 \bullet, 93,97]$ & Stigma and discrimination & $\begin{array}{l}{[14 \bullet \bullet, 47,65 \bullet, 67,73,88,89,95,98 \bullet} \\
99-102]\end{array}$ \\
\hline \multirow[t]{2}{*}{ [94-96] } & Social networks, community and institutional supports & {$[47,65 \bullet, 67,73,101,105]$} \\
\hline & Healthcare access and quality & {$[1 \bullet \bullet, 12,89][47,111][102][112]$} \\
\hline $\begin{array}{l}{[1 \bullet \bullet, 10 \bullet, 12,33,54,89,95,96} \\
\quad 106-108]\end{array}$ & Mistrust in healthcare institutions & {$[1 \bullet \bullet, 12,47,89,102,112]$} \\
\hline \multirow[t]{2}{*}[10^{\bullet},12,33,53,54,82,96,107-110]{} & $\begin{array}{l}\text { Barriers to access: health insurance coverage, reduced fund- } \\
\text { ing of services and other structural factors }\end{array}$ & {$[2 \bullet \bullet, 51,67,68,98 \bullet, 101]$} \\
\hline & Educational access and quality & \\
\hline$[23,26,28,30,53,55]$ & Education achievement & {$[45,87,100,112,113]$} \\
\hline
\end{tabular}

some studies indicated a higher mortality rate for Black

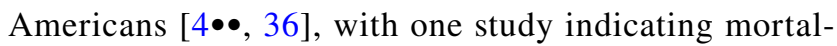
ity rates among Black Americans at 15 to $51 \%$ in varied midwestern cities [5]. Hispanic/Latino patients were also found to be more susceptible to COVID-19 [37], having the highest number of positive cases among 33 identified hotspots across the country [19] and a higher hospitalization rate $(46 \%)$ in comparison to Black Americans treated for COVID-19 in a Boston-based hospital sample [7]. Additionally, Hispanic/Latino patients may have presented COVID-19 related symptoms at later stages possibly due to undocumented status and limited English ability [12, 38]. Those with lower English proficiency were shown to be particularly vulnerable as studies demonstrated that monolingual or non-English speakers were at increased odds for COVID-19-related cases [39] and hospital admissions [38, 40] but not deaths [39]. An exception to these findings of the disparate impact on racial minorities is a cohort study of 5900 patients admitted to a New Yorkbased academic medical center in the spring of 2020 [41]. While it found that Black and Hispanic/Latino patients were more likely to test positive for COVID-19 compared to non-Hispanic whites, the survival rate from the disease did not differ by race or ethnicity after adjusting for age, sex, and related-comorbidities [41].

\section{HIV and Racial Health Inequities}

As the COVID-19 pandemic raged throughout 2020, Black and Hispanic/Latino communities were already confronting another epidemic, particularly among young gay, bisexual and other men who have sex with men

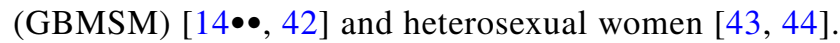
HIV rates within these racial groups have risen to a staggering rate [42, 45]. In 2018, Black Americans accounted for $42 \%$ and Hispanic/Latino Americans for $27 \%$ of new HIV diagnoses, despite comprising only $13 \%$ and $18 \%$ of the total US population, respectively [46]. In-depth qualitative interviews conducted among 50 racial minority GBMSM community and organizational leaders described the need for more awareness about biomedical HIV interventions, such as PrEP, to help reduce HIV 

minants of Health (SDOH) Framework and Communities' Vulnerability to COVID-19 and HIV
Fig. 2 The CDC's Social Deter-

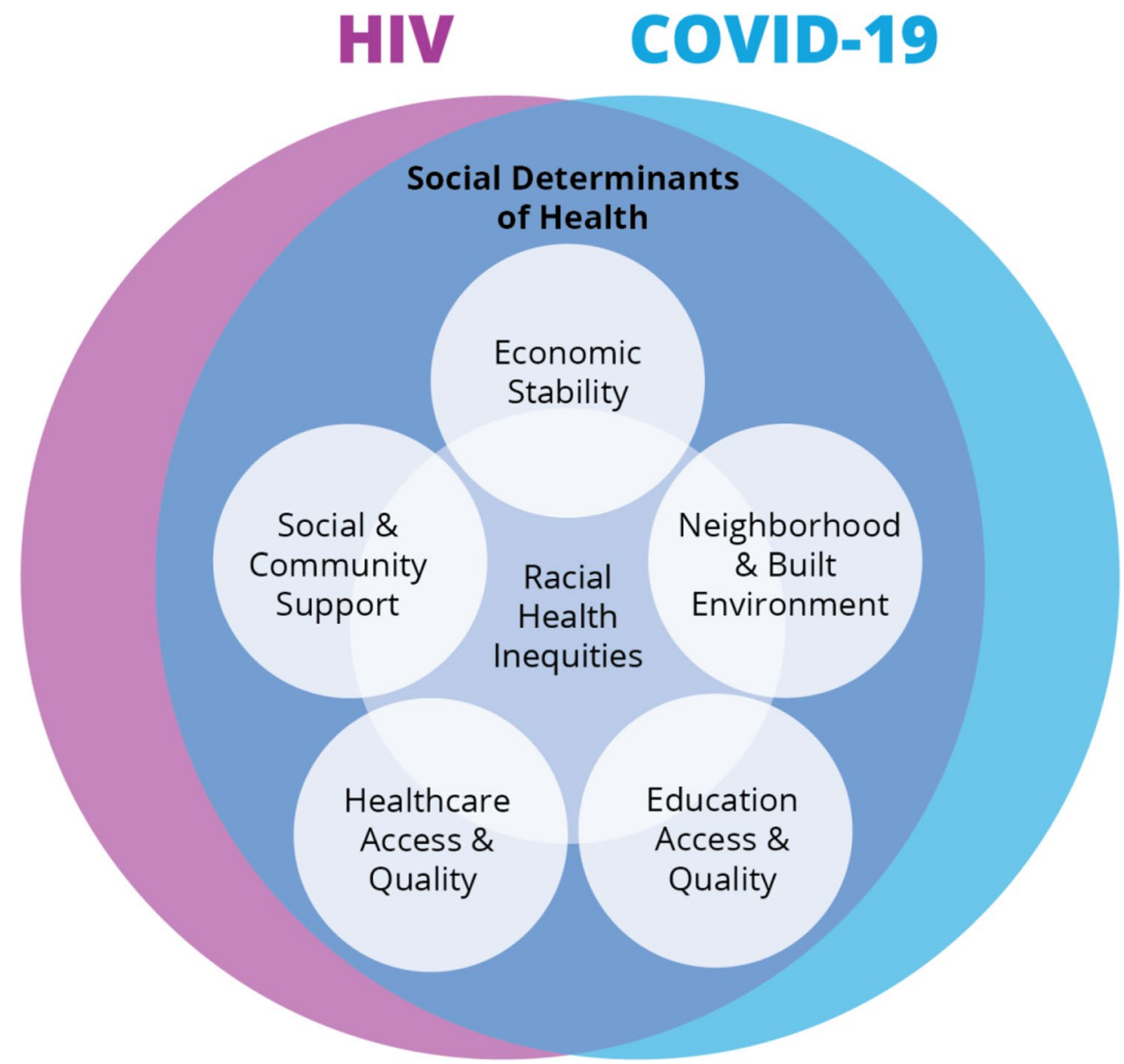

transmission [47]. Black and Hispanic/Latina women are also at increased risk for HIV accounting for 57\% and $18 \%$ at of all new HIV diagnoses among all women in the USA, respectively [46]. Previous studies showed that a 93\% excess of incident HIV infections occur among Black women in comparison to the HIV incidence rate among White women [43], and that these disparities are most evident in the Northeastern and Southern USA [48]. Black community and organizational leaders indicated that gender equity, social capital, and cultural mores, such as monogamy and abstinence, were viewed as protective and could be leveraged to lower HIV risk, particularly among Black women [49]. Finally, among people living with HIV (PLWH), one study found no significant difference between White men and Hispanic/Latino Americans regardless of gender, and a small difference among Black Americans, on their engagement with HIV care, after adjusting for factors including disease stage, age, and poverty [50]. Gender may be a be factor as antiretroviral (ART) adherence and viral suppression appear to be lower among Black women, compared to Hispanic/Latina and white women [51].

\section{Social Determinants of Health (SDOH)}

\section{Economic Stability: Income Inequities and Employment}

\section{Economic Stability and COVID-19}

As the income gap in the USA continues to grow, researchers point to the parallel disparities in health, particularly among those living at and below the poverty line who have been disproportionately affected by both COVID-19 and HIV [ $1 \bullet \bullet, 4 \bullet \bullet, 15]$. Previous studies demonstrate higher rates of COVID-19-related cases [11•, 22, 52], hospitalizations [9•, 25, 52], and deaths [12, 53] among those living in economically disadvantaged, and often more racially diverse areas. The intersection of socio-economic status and race magnifies vulnerabilities associated with poorer COVID-19 health outcomes for certain groups $[11 \bullet, 12,52]$. One study of 1800 patients that found nearly 8 times higher risk of COVID-19 detection among its low-income Black patients compared to their White counterparts [22]. Another study of 2026 US counties found a 67\% higher COVID-19 death 
rate for counties in the lowest quintile of economic privilege [53]. The arrival of COVID-19 also brought mass unemployment around the country, especially for racial groups who were overrepresented in the retail, restaurant, and hospitality industries $[1 \bullet \bullet, 54]$. Currently, the unemployment rate among Black versus white workers are two times higher with fewer opportunities to regain wealth after the COVID-19 pandemic [12]. These realities mirror the aftermath of the 2008 recession when White workers bounced back faster than other workers of color [12]. As such unemployment [55], along with the loss of employer issued health insurance $[33,54]$ led to poorer COVID-19-related health outcomes.

Individuals employed in essential industries during the pandemic, including those working in healthcare, manufacturing, waste management, construction, and warehouse sectors, were found to have higher public transportation use and lowered ability to maintain social distancing due to working outside of the home [23, 56-58]. One study estimated that approximately $16 \%$ of Hispanic/Latino and $20 \%$ of Black workers worked from home as opposed to $30 \%$ of White and $37 \%$ of Asian workers [12]. Additionally, among those who were diagnosed with COVID-19 and reported likely acquiring it at their workplace, $73 \%$ identified as Hispanic or Non-White [13]. Essential workers not only put themselves at risk for COVID-19 but by extension put at risk those living in their household, with staggering implications for multigenerational households. Using pre-pandemic data, researchers estimated $64.5 \%$ of Hispanic adults with higher risk for severe illness lived in households with at least one worker unable to work from home while Black residents were 1.6 times more likely than White residents to live with a health sector worker [59].

\section{Economic Stability and HIV}

Income inequality plays an important role in HIV susceptibility as well $[45,60 \bullet, 61,62,63,64,65 \bullet]$. Previous studies demonstrated that residents living in high poverty US counties [45], neighborhood zip codes [66], US cities [65•], and census tracts [62, 63] had higher HIV diagnoses rates, even after controlling for other demographic factors such as marital status, education, race, and age. Interestingly, one study using an analytic sample of adolescents found that neighborhood-poverty-based differences were not significant in HIV and STI prevalence [60•]. Yet other studies have found that in certain populations, including GBMSM $[61,67]$ and Black women $[67,68]$, the risk for HIV acquisition and mortality increased for those living in higher poverty areas compared to similar populations living in lower poverty areas [67]. Researchers examining the cause behind rising HIV diagnoses and death rates among GBMSM of color, particularly in the deep US southern states, point to the higher-than-average poverty rate and limited opportunities for employment, health care access, and educational achievement [67]. Lastly, people living with
HIV (PLWH) appear to be more susceptible to the negative effects of living in high poverty areas as it is associated with lower quality of life [69], unsuppressed viral load and poorer linkage to HIV care [70-72], as well as inadequate social support and health service utilization [73, 74]. Conversely, employment stability has been shown to improve or maintain HIV care engagement among PLWH $[75,76]$.

\section{Neighborhood and Built Environment: Housing and Population Density}

\section{Neighborhood and Built Environment and COVID-19}

COVID-19 brought to light the importance of the built environment in mitigating infectious disease [10•, 11•, 77]. Previous studies demonstrated that higher household density, defined as residences with more than one person per room, multigenerational households, or overcrowded homes increased the transmission risk of COVID-19 among Hispanic/Latino Americans [12, 23, 39, 52, 78]. While both Black and Hispanic/Latino residents were found to have a higher likelihood of receiving a COVID19 diagnosis if they lived in more densely populated communities [79], a spatial analysis of COVID-19 hotspots indicated that housing density had a stronger association with hotspots than population density [23]. Additionally, low-income families situated in more coveted and gentrified urban areas with rising property and rental rates find themselves being led to crowd in or "double up" within tightly spaced homes $[58,80]$. Communities of color are particularly vulnerable to housing displacement, as Black women often face eviction after a job loss [81] while up to $70 \%$ of African and Southeast Asian refugee families living in the Southeast USA reported fear of income loss during the pandemic [82]. Hispanic/Latino adults were also found to have higher prevalence of psychosocial stress compared to other racial groups, due to concerns of not having enough food or stable housing during the COVID-19 pandemic [83]. The lack of housing stability was also found to be associated with COVID-19, as $24 \%$ of COVID-related hospital admissions were among those experiencing homelessness [7]. With lower access to hygiene facilities, living with others in congregate settings, and higher rates of chronic physical and mental illness, those experiencing homelessness were shown to be at higher risk for COVID-19 acquisition [84].

\section{Neighborhood and Built Environment and HIV}

While high housing density has not shown to be a significant factor in mitigating HIV transmission, 
housing stability has been found to help improve HIV care engagement among PLWH [72, 77, 85-87]. Among PLWH who received housing support, $86 \%$ indicated viral suppression success [72]. Stable housing offers PLWH increased access to social support and health care services as well as lowers their risk of assault and coercion [77, 85]. Additionally, in a study that examined a 2018 outbreak of HIV among people who inject drugs (PWID), increased homelessness was cited as one of the likely factors behind the outbreak [86]. Demographic density also appears to reduce HIV acquisition, particularly for men who have sex with men (MSM). MSM living in areas with a higher percentage of lesbian, gay, bisexual and transgender (LGBT) persons were found to have a lower HIV diagnosis rate compared to MSM living in less LGBT-populous communities, suggesting that living in more LGBT-friendly communities can be protective against HIV transmission [61].

\section{Social and Community Support: Stigma, Discrimination, Norms and Social Networks}

\section{Social and Community Support and COVID-19}

Infectious diseases have long been viewed as "foreign" entities brought to the USA by non-citizens who are believed to be "different" from the general population [14••, 88]. In the 1980s, initially Black Haitian foreigners then eventually young, predominantly white gay men, were stigmatized owing to a then-emerging virus now known as HIV and AIDS [88, 89], while in 2020, the former US president aimed to characterize COVID-19 as a "Chinese virus," which lead to a wave of xenophobic acts across the country [89, 90, 91]. Specific populations who are viewed to be "carriers" of particular infectious diseases are subjected to discriminatory behavior by the general public, which can lead to isolation and overall poorer quality of life. In a study conducted at the start of the COVID-19 pandemic, individuals who reported experiencing COVID-19-related discrimination, including being treated with less courtesy and respect or feeling that others are afraid of them, went up among Black and Asian US residents, from 9 to $15 \%$ and 11 to $17 \%$, respectively [92•]. Another study reported that Asian Americans' anxiety, depressive symptoms, and sleep difficulties rose $40 \%$ and experienced discrimination increased $30 \%$ since the beginning of the COVID-19 pandemic, with social support shown to buffer the negative effects of discrimination in this population [93]. A robust social network has also proven to ameliorate stigmatization and negative outcomes of COVID-19 among Black Americans, despite a study finding that collective engagement in predominately Black residential areas was associated with a higher COVID-19 diagnosis rate [94]. Within the community context, studies indicate that building a network of trusted community sources, largely via word-of-mouth, can help dispel the uncertainty and myths surrounding COVID-19 prevention and treatment among Black Americans [95, 96]. The role of trusted social networks to provide accurate information may be particularly important as Black communities have often been subjected to various unsubstantiated characterizations of being immune to certain diseases and infectious agents due to their genetic make-up [97].

\section{Social and Community Support and HIV}

Among these enduring myths is that Black Americans are not susceptible to HIV [97]. Despite the alarming rate of HIV among Black women and Black GBMSM in particular, previous studies noted that the deep religiosity, conservatism, and homophobia within the Black community have allowed this myth to thrive, thus generating intense stigma surrounding HIV [65•, 67, 73]. In fact, stigma related to HIV and same sex sexual behaviors is found to be high among Black Americans compared to other racial groups $[65 \bullet, 67,98 \bullet]$, which has impacted HIV prevention and care engagement efforts such as the willingness to test and treat HIV [67, 89]. Hispanic/ Latino and Indigenous communities have also seen a rise in HIV and attribute the rapid transmission among its members to HIV stigma and discrimination $[99,100]$. Indeed, stigma has been associated with perceived loss of status, ostracization and devaluation [89], and PLWH are acutely aware of these negative effects [73, 101, 102]. PLWH have reported reduced life chances in the form of unemployment or under-employment $[67,73]$, poor to fair self-rated health [103], and unfair treatment by health and social service professionals [47, 102].

Conversely, social support has helped mitigate HIV stigma and discrimination among PLWH [69, 73, 104]. In one study, young gay and bisexual men (GBM) and transgender women of color reported that increased interaction with other members of the LGBT community via group and community activities, such as local Pride festivals, and building informal support networks composed of allies and partners are effective in reducing stigma and can help improve HIV prevention and care engagement for this population [47]. Among Black PLWH, instrumental support from family members was shown to be beneficial in filling the gaps left by governmental social service agencies as well as in reducing stigma, as some participants stated that their interaction with family members was surprisingly positive when their HIV status was discussed [73, 105]. Yet greater societal and institutional support may also have an effect on population-level HIV incidence and treatment engagement $[65 \bullet, 67,101]$. Laws permitting same-sex 
marriage were associated with lower HIV incidence among MSM [65•], while the mortality rate among PLWH was found to be lower in US states with anti-discrimination laws [101], compared to other states without similar regulations.

\section{Healthcare Access and Quality}

\section{Healthcare Access and Quality and COVID-19}

Long before COVID-19 became a global pandemic, the documented discrimination, harm and abuse of authority within the US medical, health, and social services institutions against low-income racial minorities have generated a deep distrust among communities of color $[1 \bullet \bullet$, 12, 89]. The generational distrust of such institutions has weakened its ability to communicate appropriate and relevant COVID-19 information to racial minority communities disproportionately affected by the disease [95, 106], which has led to lower testing [96] and potentially later stage presentation of COVID-19 at the hospital [12, 107]. Early in the COVID-19 pandemic, most of the testing centers were situated in largely White and more affluent neighborhoods $[10 \bullet, 54]$, which only exacerbated the multiple healthcare-related barriers facing minority communities with increased risk for COVID-19 exposure [33, 108]. Retaining comprehensive health insurance is a significant factor, particularly for individuals who are at risk of job loss, as they may have difficulty in seeking care for COVID-related symptoms without employer-issued health insurance $[12,53,82]$. In a review of medical records for patients admitted during the early months of the pandemic, Hispanic/Latino patients were shown to have a higher percentage of self-pay health insurance as well as having higher odds of testing positive for COVID-19 compared to other racial groups [109]. Finally, while telehealth services, defined as the provision of health services via telecommunication technologies, have been shown to improve health access for disparate and marginalized populations [107], new evidence indicates that low-income rural, racial minority, and elderly communities may be excluded from this novel service due to patients' lower digital technology literacy and insufficient resources of underfunded clinics and hospitals $[96,110]$.

\section{Healthcare Access and Quality and HIV}

Mistrust of healthcare and social services institutions is particularly evident among PLWH, with a focus on provider-level issues and interactions [47, 111]. Previous studies demonstrated that HIV stigma perpetuated by health care and social services providers is a source of concern among racial minority PLWH [102] and is associated with low linkages to care after an HIV diagnosis [112]. Additionally, community clinics facing fiscal constraints, especially in low-income and racially segregated neighborhoods, have left PLWH with restricted choices for HIV services due to reduced clinic hours and minimum staff availability [98•]. Low-income PLWH must also contend with the limited availability of health services for public health insurance recipients, which has been shown to influence the availability and quality of HIV care in this population $[2 \bullet \bullet, 68,101]$. For example, previous studies indicated that optimal HIV viral suppression is associated with the use of private versus public health insurance and clinics [51], while the mortality risk among PLWH was lower for those living in states with greater health care coverage $[68,101]$. Yet not all areas of the country are afforded equal healthcare availability as evidenced in the southern US states, wherein physician visits and pharmacy benefits are heavily regulated due to restrictive Medicaid provisions [67]. These southern US states must rely on other federal programs, such as the Ryan White Care program, to provide sufficient HIV care for PLWH [67].

\section{Educational Access and Quality}

Multiple studies demonstrate that educational achievement, along with other social determinants such as employment, healthcare availability, and poverty, can impact COVID19-related transmission [23, 28], hospital admissions [26], and deaths $[30,53,55]$. Areas with a higher percentage of residents without a high school diploma are associated with increased COVID-19-related mortality rates [28, 30, 53], while hospital admissions during the early months of the COVID-19 pandemic was shown to be correlated with neighborhoods with the least proportion of residents with a college degree [26]. Similarly, HIV care engagement, including optimal viral suppression, appears to be lower among PLWH who did not complete a high school education [87, 112]. However, educational achievement was not found to be correlated with HIV transmission [45, 113], despite the expectation that higher levels of education is equated with better health outcomes [100]. In studies examining the rates of HIV diagnoses within the state of Mississippi [113] and in a sample of 1560 counties across the USA [45], having less than a high school education was either negatively associated with [113] or not indicated [45] for higher HIV diagnoses rates. 


\section{Conclusion}

This literature review clearly demonstrates the socially determined health inequities among communities of color deeply affected by COVID-19 and HIV. Such inequities are a result of racialized realities that are impacted by economic instability, the built environment, limited healthcare access and quality as well as lowered educational opportunities. Additionally, stigma and discrimination have shown to exacerbate these health inequities but can be mitigated by social and community-level supports. The structural and systematic factors that drive HIV and COVID-19 transmission highlight the importance of not solely focusing on biomedical interventions as solutions to ending HIV and COVID-19, but rather call for building a more just public health and social service safety net that meets the needs of people at the intersection of multiple vulnerabilities.

Author contribution Conceptualization, RMB, PMF, IWH, AM; methodology, RMB, PMF, IWH, LC, CH, KB; formal analysis, RMB, LC, $\mathrm{CH}$.; writing-original draft preparation, $\mathrm{RMB}, \mathrm{LC}, \mathrm{CH}, \mathrm{PMF}$; writing-review and editing, RMB, PMF, IWH, LC, AM, EW, KB.

Funding Dr. Beltran is supported by the National Institutes of Health under award number T32MH080634. The content is solely the responsibility of the authors and does not necessarily represent the official views of the National Institutes of Health.

Dr. Holloway acknowledges support from the National Institute of Mental Health (P30 MH58107) and the California HIV/AIDS Research Program (RP15-LA-007).

\section{Availability of data and material N/A}

Code availability N/A.

\section{Declarations}

Conflict of interest The authors declare no competing interests. Ethics approval Human and Animal Ethics Statement: This article does not contain any studies with human or animal subjects.

Consent for publication All authors have read and agreed to the published version of the manuscript.

Open Access This article is licensed under a Creative Commons Attribution 4.0 International License, which permits use, sharing, adaptation, distribution and reproduction in any medium or format, as long as you give appropriate credit to the original author(s) and the source, provide a link to the Creative Commons licence, and indicate if changes were made. The images or other third party material in this article are included in the article's Creative Commons licence, unless indicated otherwise in a credit line to the material. If material is not included in the article's Creative Commons licence and your intended use is not permitted by statutory regulation or exceeds the permitted use, you will need to obtain permission directly from the copyright holder. To view a copy of this licence, visit http://creativecommons.org/licenses/by/4.0/.

\section{References}

Papers of particular interest, published recently, have been highlighted as:

- Of importance

$\bullet$ Of major importance

1.• Galea S, Abdalla SM. COVID-19 pandemic, unemployment, and civil unrest: underlying deep racial and socioeconomic divides. JAMA. 2020;324:227-8. This commentary offers a deep historical and contemporary analysis of the racial and social causes of health disparities in the U.S.

2.•• Millett GA. New pathogen, same disparities: why COVID-19 and HIV remain prevalent in US communities of colour and implications for ending the HIV epidemic. J Int AIDS Soc. 2020;23:e25639. This commentary focuses on the impact of HIV and COVID-19 on Black and Brown communities in the U.S. and posed three significant challenges facing the Ending the HIV Epidemic (EHE) initiative with the advent of COVID-19.

3. Harris OO, Leblanc N, McGee K, Randolph S, Wharton MJ, Relf M. Alarm at the gate- health and social inequalities are comorbid conditions of HIV and COVID-19. J Assoc Nurses AIDS Care. 2020;31:367-75.

4.•• Fields EL, Copeland R, Hopkins E (2021) Same script, different viruses: HIV and COVID-19 in US Black communities. Lancet. This commentary uses historical and contemporary issues to examine the impact of COVID-19 and HIV, specifically among Black Americans, and offers lessons to be learned for policy makers, public health practitioners and health providers.

5. Holmes L Jr, Enwere M, Williams J, et al. Black-white risk differentials in COVID-19 (SARS-COV2) transmission, mortality and case fatality in the United States: translational epidemiologic perspective and challenges. Int J Env Res Public Heal. 2020. https://doi.org/10.3390/ijerph17124322.

$6 . \bullet$ Poteat T, Millett GA, Nelson LE, Beyrer C. Understanding COVID-19 risks and vulnerabilities among black communities in America: the lethal force of syndemics. Ann Epidemiol. 2020;47:1-3. This study uses syndemic theory to frame the interaction of multiple epidemics such as COVID-19, HIV, and substance use among Black Americans, and the historical, social and political drivers of these epidemics.

7. Hsu HE, Ashe EM, Silverstein M, et al. Race/ethnicity, underlying medical conditions, homelessness, and hospitalization status of adult patients with COVID-19 at an urban safety-net medical center - Boston, Massachusetts, 2020. MMWR Morb Mortal Wkly Rep. 2020;69:864-9.

8. Azar KMJ, Shen Z, Romanelli RJ, Lockhart SH, Smits K, Robinson S, Brown S, Pressman AR. Disparities in outcomes among COVID-19 patients in a large health care system in California. Heal Aff. 2020;39:1253-62.

9. Raifman MA, Raifman JR. Disparities in the population at risk of severe illness from COVID-19 by race/ethnicity and income. Am J Prev Med. 2020;59:137-9. This report provides an intial analysis of race/ethinicity groups at higher risk for COVID-19.

10. Millett GA, Honermann B, Jones A, Lankiewicz E, Sherwood J, Blumenthal S, Sayas A. White counties stand apart: the primacy of residential segregation in COVID-19 and HIV diagnoses. AIDS Patient Care STDS. 2020;34:417-24. This report examines the impact of residence, segregated by race and ethinicty, on both HIV and COVID-19 diagnoses. 
11. Adhikari S, Pantaleo NP, Feldman JM, Ogedegbe O, Thorpe L, Troxel AB (2020) Assessment of community-level disparities in coronavirus disease 2019 (COVID-19) Infections and deaths in large US metropolitan areas. JAMA Netw Open $3:$ e2016938. This report uses multiple data sources to examine neigborhood poverty and race and ethnicity association with COVID-19 incidence and related deaths in the 10 major U.S. Cities.

12. Haynes N, Cooper LA, Albert MA, Association of black C. at the heart of the matter: unmasking and addressing the toll of COVID-19 on diverse populations. Circulation. 2020;142:105-7.

13. Bui DP, McCaffrey K, Friedrichs M, et al. Racial and ethnic disparities among COVID-19 cases in workplace outbreaks by industry sector - Utah, March 6-June 5, 2020. MMWR Morb Mortal Wkly Rep. 2020;69:1133-8.

14.•• Bowleg L (2020) We're not all in this together: on COVID-19, intersectionality, and structural inequality. This commentary uses the frame of critical theory and intersectionality to focus on the structural inequalities that prevent Black and Brown communities from receiving equal HIV and COVID-19 care.

15. Hargreaves J, Davey C, Auerbach J, Blanchard J, Bond V, Bonell C, Burgess R, Busza J, Colbourn T, Cowan F. Three lessons for the COVID-19 response from pandemic HIV. Lancet HIV. 2020;7:e309-11.

16. Walensky RP (2021) Media statement from CDC Director Rochelle Walensky, MD, MPH, on racis and health. Centers Dis. Control Prev.

17. Moher D, Liberati A, Tetzlaff J, Altman DG. Preferred reporting items for systematic reviews and meta-analyses: the PRISMA statement. Int J Surg. 2010;8:336-41.

18. Phelan JC, Link BG. Is racism a fundamental cause of inequalities in health? Annu Rev Sociol. 2015;41:311-30.

19. Moore JT, Ricaldi JN, Rose CE, et al. Disparities in incidence of COVID-19 among underrepresented racial/ethnic groups in counties identified as hotspots during June 5-18, 2020-22 States, February-June 2020. MMWR Morb Mortal Wkly Rep. 2020;69:1122-6.

20. Kaufman HW, Niles JK, Nash DB. Disparities in SARS-CoV-2 positivity rates: associations with race and ethnicity. Popul Heal Manag. 2020. https://doi.org/10.1089/pop.2020.0163.

21. Rozenfeld Y, Beam J, Maier H, Haggerson W, Boudreau K, Carlson J, Medows R. A model of disparities: risk factors associated with COVID-19 infection. Int J Equity Health. 2020;19:126.

22. Khanna N, Klyushnenkova EN, Kaysin A. Association of COVID-19 with race and socioeconomic factors in family medicine. J Am Board Fam Med. 2021;34:S40-7.

23. Maroko AR, Nash D, Pavilonis BT. COVID-19 and inequity: a comparative spatial analysis of New York City and Chicago Hot Spots. J Urban Heal. 2020;97:461-70.

24. Patel AP, Paranjpe MD, Kathiresan NP, Rivas MA, Khera A V (2020) Race, socioeconomic deprivation, and hospitalization for COVID-19 in English participants of a National Biobank. medRxiv Prepr Serv Heal Sci. https://doi.org/10.1101/2020.04. 27.20082107

25. Prasannan L, Rochelson B, Shan W, Nicholson K, Solmonovich R, Kulkarni A, Lewis D, Greenberg M, Nimaroff M, Blitz MJ (2021) Social determinants of health and coronavirus disease 2019 in pregnancy: condensation: social determinants of health, including neighborhood characteristics such as household income and educational attainment, are associated with SARS-CoV-2 infection an. Am J Obstet Gynecol MFM 100349

26. Wadhera RK, Wadhera P, Gaba P, Figueroa JF, Joynt Maddox KE, Yeh RW, Shen C. Variation in COVID-19 hospitalizations and deaths across New York City Boroughs. JAMA. 2020;323:2192-5.
27. Holtgrave DR, Barranco MA, Tesoriero JM, Blog DS, Rosenberg ES. Assessing racial and ethnic disparities using a COVID-19 outcomes continuum for New York State. Ann Epidemiol. 2020;48:9-14.

28. Li D, Gaynor SM, Quick C, Chen JT, Stephenson BJK, Coull BA, Lin X (2020) Unraveling US national COVID-19 racial/ ethnic disparities using county level data among 328 million Americans. medRxiv Prepr Serv Heal Sci. https://doi.org/10. 1101/2020.12.02.20234989

29. Yu Q, Salvador C, Melani I, Berg M, Kitayama S (2020) The lethal spiral: racial segregation and economic disparity jointly exacerbate the COVID-19 fatality in large American cities.

30. Seligman B, Ferranna M, Bloom DE. Social determinants of mortality from COVID-19: a simulation study using NHANES. PLoS Med. 2021;18:e1003490.

31. Alsan M, Stantcheva S, Yang D, Cutler D. Disparities in coronavirus 2019 reported incidence, knowledge, and behavior among US adults. JAMA Netw Open. 2020;3:e2012403.

32. Akanbi MO, Rivera AS, Akanbi FO, Shoyinka A (2020) An ecologic study of disparities in COVID-19 incidence and case fatality in Oakland County, MI, USA, during a state-mandated shutdown. J racial Ethn Heal disparities $1-8$

33. Snowden LR, Graaf G. COVID-19, Social determinants past, present, and future, and African Americans' health. J racial Ethn Heal disparities. 2021;8:12-20.

34. Munoz-Price LS, Nattinger AB, Rivera F, Hanson R, Gmehlin CG, Perez A, Singh S, Buchan BW, Ledeboer NA, Pezzin LE. Racial disparities in incidence and outcomes among patients with COVID-19. JAMA Netw Open. 2020;3:e2021892.

35. Renelus BD, Khoury NC, Chandrasekaran K, Bekele E, Briggs WM, Ivanov A, Mohanty SR, Jamorabo DS. Racial disparities in COVID-19 hospitalization and in-hospital mortality at the height of the New York City pandemic. J Racial Ethn Heal Disparities. 2020. https://doi.org/10.1007/ s40615-020-00872-x.

36. Mahajan UV, Larkins-Pettigrew M. Racial demographics and COVID-19 confirmed cases and deaths: a correlational analysis of 2886 US counties. J Public Heal. 2020;42:445-7.

37. Clay LA, Rogus S. Primary and secondary health impacts of COVID-19 among minority individuals in New York State. Int J Environ Res Public Health. 2021. https://doi.org/10.3390/ ijerph18020683.

38. Ingraham NE, Purcell LN, Karam BS, Dudley RA, Usher MG, Warlick CA, Allen ML, Melton GB, Charles A, Tignanelli CJ (2020) Racial/ethnic disparities in hospital admissions from COVID-19 and determining the impact of neighborhood deprivation and primary language. medRxiv. https://doi.org/10. 1101/2020.09.02.20185983

39. Rodriguez-Diaz CE, Guilamo-Ramos V, Mena L, et al. Risk for COVID-19 infection and death among Latinos in the United States: examining heterogeneity in transmission dynamics. Ann Epidemiol. 2020;52:46-53.e2.

40. Blitz MJ, Rochelson B, Prasannan L, Shan W, Chervenak FA, Nimaroff M, Bornstein E (2020) Racial and ethnic disparity and spatiotemporal trends in severe acute respiratory syndrome coronavirus 2 prevalence on obstetrical units in New York. Am J Obstet Gynecol MFM 2:100212

41. Kabarriti R, Brodin NP, Maron MI, Guha C, Kalnicki S, Garg MK, Racine AD. Association of race and ethnicity with comorbidities and survival among patients with COVID-19 at an urban medical center in New York. JAMA Netw open. 2020;3:e2019795-e2019795.

42. Chapin-Bardales J, Rosenberg ES, Sullivan PS. Trends in racial/ ethnic disparities of new AIDS diagnoses in the United States, 1984-2013. Ann Epidemiol. 2017;27:329-334.e2. 
43. Bradley ELP, Williams AM, Green S, Lima AC, Geter A, Chesson HW, McCree DH. Disparities in incidence of human immunodeficiency virus infection among Black and White women — United States, 2010-2016. MMWR Morb Mortal Wkly Rep. 2019;68:416-8.

44. McCree DH, Chesson H, Bradley ELP, Lima A, Fugerson AG. US regional changes in racial/ethnic disparities in HIV Diagnoses among women in the United States, 2012 and 2017. AIDS Behav. 2020;24:1118-23.

45. Gant Z, Lomotey M, Hall HI, Hu X, Guo X, Song R. A countylevel examination of the relationship between HIV and social determinants of health: 40 states, 2006-2008. Open AIDS J. 2012;6:1.

46. Center for Disease Control and Prevention (2018) Diagnoses of HIV Infection in the United States and Dependent Areas, 2018. Atlanta, GA

47. Mann-Jackson L, Alonzo J, Garcia M, Trent S, Bell J, Horridge DN, Rhodes SD. Using community-based participatory research to address STI/HIV disparities and social determinants of health among young GBMSM and transgender women of colour in North Carolina. USA: Health Soc Care Community; 2020. https://doi.org/10.1111/hsc.13268.

48. McCree DH, Sutton M, Bradley E, Harris N. Changes in the disparity of HIV diagnosis rates among Black women United States, 2010-2014. MMWR Morb Mortal Wkly Rep. 2017;66:104-6.

49. Brawner BM, Reason JL, Hanlon K, Guthrie B, Schensul JJ. Stakeholder conceptualisation of multi-level HIV and AIDS determinants in a Black epicentre. Cult Health Sex. 2017;19:948-63.

50. Beer L, Mattson CL, Bradley H, Skarbinski J. Understanding cross-sectional racial, ethnic, and gender disparities in antiretroviral use and viral suppression among HIV patients in the United States. Medicine (Baltimore). 2016;95:e3171.

51. Geter A, Sutton MY, Armon C, Buchacz K. Disparities in viral suppression and medication adherence among women in the USA, 2011-2016. AIDS Behav. 2019;23:3015-23.

52. Lewis NM, Friedrichs M, Wagstaff S, et al. Disparities in COVID-19 incidence, hospitalizations, and testing, by arealevel deprivation - Utah, March 3-July 9, 2020. MMWR Morb Mortal Wkly Rep. 2020;69:1369-73.

53. Dalsania AK, Fastiggi MJ, Kahlam A, Shah R, Patel K, Shiau S, Rokicki S, DallaPiazza M (2021) The relationship between social determinants of health and racial disparities in COVID-19 mortality. J racial Ethn Heal disparities 1-8

54. Kirksey L, Tucker DL, Taylor EJ, White Solaru KT, Modlin CSJ. Pandemic superimposed on epidemic: Covid-19 disparities in Black Americans. J Natl Med Assoc. 2021;113:39-42.

55. Paul R, Arif A, Pokhrel K, Ghosh S. The association of social determinants of health with COVID-19 mortality in rural and urban counties. J Rural Heal Off J Am Rural Heal Assoc Natl Rural Heal Care Assoc. 2021. https://doi.org/10.1111/jrh.12557.

56. Rogers TN, Rogers CR, VanSant-Webb E, Gu LY, Yan B, Qeadan F. Racial disparities in COVID-19 mortality among essential workers in the United States. World Med Heal Policy. 2020. https://doi.org/10.1002/wmh3.358.

57. Sy KTL, Martinez ME, Rader B, White LF. Socioeconomic disparities in subway use and COVID-19 outcomes in New York City. Am J Epidemiol. 2020. https://doi.org/10.1093/aje/kwaa277.

58. Huang VS, Sutermaster S, Caplan Y, Kemp H, Schmutz D, Sgaier SK (2020) Social distancing across vulnerability, race, politics, and employment: how different Americans changed behaviors before and after major COVID-19 policy announcements. medRxiv
59. Selden TM, Berdahl TA. COVID-19 and racial/ethnic disparities in health risk, employment, and household composition. Heal Aff. 2020;39:1624-32.

60. Zullo AR, Adams JW, Gantenberg JR, Marshall BDL, Howe CJ. Examining neighborhood poverty-based disparities in HIV/ STI prevalence: an analysis of add health data. Ann Epidemiol. 2019;39:8-14.e4. This study did not find any neigborhood poverty-based difference in HIV and STI prevelance among U.S. adolescents.

61. Forsyth AD, Valdiserri RO. A state-level analysis of social and structural factors and HIV outcomes among men who have sex with men in the United States. AIDS Educ Prev. 2015;27:493-504.

62. Johnson Lyons S, Gant Z, Jin C, Dailey A, Nwangwu-Ike N, Satcher Johnson A (2021) A census tract-level examination of differences in social determinants of health among people with HIV, by race/ethnicity and geography, United States and Puerto Rico, 2017. Public Health Rep 33354921990373

63. Gibson C, Grande K, Schumann C, Gasiorowicz M. Census tract poverty and racial disparities in HIV rates in Milwaukee County, Wisconsin, 2009-2014. AIDS Behav. 2018;22:2994-3002.

64. Pellowski JA, Kalichman SC, Matthews KA, Adler N. A pandemic of the poor: social disadvantage and the US HIV epidemic. Am Psychol. 2013;68:197.

65.• Buot M-LG, Docena JP, Ratemo BK, Bittner MJ, Burlew JT, Nuritdinov AR, Robbins JR. Beyond race and place: distal sociological determinants of HIV disparities. PLoS One. 2014;9:e91711. This study results support an ecological model wherein poverty, income and social inequality synergistically drive HIV transmission in the U.S.

66. Wiewel EW, Bocour A, Kersanske LS, Bodach SD, Xia Q, Braunstein SL. The association between neighborhood poverty and HIV diagnoses among males and females in New York City, 2010-2011. Public Health Rep. 2016;131:290-302.

67. Reif S, Safley D, McAllaster C, Wilson E, Whetten K. State of HIV in the US deep south. J Community Health. 2017;42:844-53.

68. Watson L, Gant Z, Hu X, Johnson AS. Exploring social determinants of health as predictors of mortality during 2012-2016, among Black women with diagnosed HIV Infection attributed to heterosexual contact, United States. J racial Ethn Heal disparities. 2019;6:892-9.

69. Ghiasvand H, Higgs P, Noroozi M, Ghaedamini Harouni G, Hemmat M, Ahounbar E, Haroni J, Naghdi S, Nazeri Astaneh A, Armoon B. Social and demographical determinants of quality of life in people who live with HIV/AIDS infection: evidence from a meta-analysis. Biodemography Soc Biol. 2020;65:57-72.

70. Rojas D, Melo A, Moise IK, Saavedra J, Szapocznik J. The association between the social determinants of health and HIV control in Miami-Dade county ZIP codes, 2017. J racial Ethn Heal disparities. 2020. https://doi.org/10.1007/s40615-020-00838-z.

71. Cope AB, Edmonds A, Ludema C, et al. Neighborhood poverty and control of HIV, hypertension, and diabetes in the women's interagency HIV study. AIDS Behav. 2020;24:2033-44.

72. Griffin A, Dempsey A, Cousino W, Avery L, Phillips H, Egwim $\mathrm{E}$, Cheever L. Addressing disparities in the health of persons with HIV attributable to unstable housing in the United States: the role of the Ryan White HIV/AIDS Program. PLoS Med. 2020;17:e1003057.

73. Sprague C, Brown SM, Simon S, McMahan LD, Kassiel I, Konkle-Parker D. Towards ending the US HIV epidemic by 2030: understanding social determinants of health and HIV in Mississippi. Glob Public Health. 2020;15:31-51.

74. Abbott LS, Williams CL. Influences of social determinants of health on African Americans living with HIV in the rural 
southeast: a qualitative meta-synthesis. J Assoc Nurses AIDS Care. 2015;26:340-56.

75. Conyers LM, Richardson LA, Datti PA, Koch LC, Misrok M. A critical review of health, social, and prevention outcomes associated with employment for people living with HIV. AIDS Educ Prev Off Publ Int Soc AIDS Educ. 2017;29:475-90.

76. Maulsby CH, Ratnayake A, Hesson D, Mugavero MJ, Latkin CA. A scoping review of employment and HIV. AIDS Behav. 2020;24:2942-55.

77. Riley ED, Hickey MD, Imbert E, Clemenzi-Allen AA, Gandhi M (2020) COVID-19 and HIV spotlight the US imperative for permanent affordable housing. Clin. Infect. Dis. an Off. Publ. Infect. Dis. Soc. Am.

78. Figueroa JF, Wadhera RK, Lee D, Yeh RW, Sommers BD (2020) Community-level factors associated with racial and ethnic disparities in COVID-19 rates in Massachusetts. Heal Aff 101377hlthaff202001040

79. Vahidy FS, Nicolas JC, Meeks JR, et al. Racial and ethnic disparities in SARS-CoV-2 pandemic: analysis of a COVID-19 observational registry for a diverse US metropolitan population. BMJ Open. 2020;10:e039849.

80. Arcaya MC, Nidam Y, Binet A, Gibson R, Gavin V. Rising home values and Covid-19 case rates in Massachusetts. Soc Sci Med. 2020;265:113290.

81. Obinna DN. Essential and undervalued: health disparities of African American women in the COVID-19 era. Ethn Health. 2021;26:68-79.

82. Feinberg I, O'Connor MH, Owen-Smith A, Dube SR. Public health crisis in the refugee community: little change in social determinants of health preserve health disparities. Health Educ Res. 2021. https://doi.org/10.1093/her/cyab004.

83. McKnight-Eily LR, Okoro CA, Strine TW, Verlenden J, Hollis ND, Njai R, Mitchell EW, Board A, Puddy R, Thomas C. Racial and ethnic disparities in the prevalence of stress and worry, mental health conditions, and increased substance use among adults during the COVID-19 pandemic - United States, April and May 2020. MMWR Morb Mortal Wkly Rep. 2021;70:162-6.

84. Tsai J, Wilson M. COVID-19: a potential public health problem for homeless populations. Lancet Public Heal. 2020;5:e186-7.

85. Aidala AA, Wilson MG, Shubert V, Gogolishvili D, Globerman J, Rueda S, Bozack AK, Caban M, Rourke SB. Housing status, medical care, and health outcomes among people living with HIV/AIDS: a systematic review. Am J Public Health. 2016;106:e1-23.

86. Kim MM, Conyngham SC, Smith C, Higgins D, Nassau $\mathrm{T}$, Terrell C, Brady KA. Understanding the intersection of behavioral risk and social determinants of health and the impact on an outbreak of human immunodeficiency virus among persons who inject drugs in Philadelphia. J Infect Dis. 2020;222:S250-8.

87. Glynn TR, Safren SA, Carrico AW, Mendez NA, Duthely LM, Dale SK, Jones DL, Feaster DJ, Rodriguez AE. High levels of syndemics and their association with adherence, viral non-suppression, and biobehavioral transmission risk in Miami, a US city with an HIV/AIDS epidemic. AIDS Behav. 2019;23:2956-65.

88. Logie CH, Turan JM. How do we balance tensions between COVID-19 public health responses and stigma mitigation? Learning from HIV research. AIDS Behav. 2020;24:2003-6.

89. Eaton LA, Kalichman SC. Social and behavioral health responses to COVID-19: lessons learned from four decades of an HIV pandemic. J Behav Med. 2020;43:341-5.
90. Ramirez-Valles J, Breton E, Chae DH, Haardörfer R, Kuhns LM. The COVID-19 pandemic: everything old is new again in public health education. Health Educ Behav. 2020;47:501-3.

91. Wang D, Gee GC, Bahiru E, Yang EH, Hsu JJ. Asian-Americans and Pacific islanders in COVID-19: emerging disparities amid discrimination. J Gen Intern Med. 2020;35:3685-8.

92.• Liu Y, Finch BK, Brenneke SG, Thomas K, Le PD. Perceived discrimination and mental distress amid the COVID-19 pandemic: evidence from the understanding America study. Am J Prev Med. 2020;59:481-92. This study's results indicate heightened percieved COVID-19 related discrimination among Black and Asian Americans, which was associated with increased mental distress.

93. Lee S, Waters SF (2020) Asians and Asian Americans' experiences of racial discrimination during the COVID-19 pandemic: impacts on health outcomes and the buffering role of social support. Stigma Heal.

94. Ransome Y, Ojikutu BO, Buchanan M, Johnston D, Kawachi I. Neighborhood social cohesion and inequalities in COVID19 diagnosis rates by area-level Black/African American racial composition. J Urban Health. 2021. https://doi.org/10.1007/ s11524-021-00532-3.

95. Farquharson WH, Thornton CJ. Debate: exposing the most serious infirmity - racism's impact on health in the era of COVID19. Child Adolesc Ment Heal. 2020;25:182-3.

96. Bateman LB, Schoenberger Y-MM, Hansen B, Osborne TN, Okoro GC, Speights KM, Fouad MN. Confronting COVID-19 in under-resourced, African American neighborhoods: a qualitative study examining community member and stakeholders' perceptions. Ethn Health. 2021;26:49-67.

97. Laurencin CT, McClinton A. The COVID-19 pandemic: a call to action to identify and address racial and ethnic disparities. J Racial Ethn Heal Disparities. 2020;7:398-402.

98. Lane SD, Rubinstein RA, Keefe RH, Webster N, Cibula DA, Rosenthal A, Dowdell J. Structural violence and racial disparity in HIV transmission. J Health Care Poor Underserved. 2004;15:319-35. This study uses the framework of structural violence to look at ecological level-risk factors for HIV among women of color in the U.S.

99. Negin J, Aspin C, Gadsden T, Reading C. HIV among indigenous peoples: a review of the literature on HIV-related behaviour since the beginning of the epidemic. AIDS Behav. 2015;19:1720-34.

100. Cianelli R, Villegas N. Social determinants of health for HIV among Hispanic women. Hisp Heal care Int Off J Natl Assoc Hisp Nurses. 2016;14:4-9.

101. Krueger AL, Van Handel M, Dietz PM, Williams WO, Johnson AS, Klein PW, Cohen S, Mandsager P, Cheever LW, Rhodes P. Factors associated with state variation in mortality among persons living with diagnosed HIV infection. J Community Health. 2019;44:963-73.

102. Geter Fugerson A, Sutton MY, Hubbard McCree D. Social and structural determinants of HIV treatment and care among Hispanic women and Latinas living with HIV infection in the United States: a qualitative review: 2008-2018. Heal equity. 2019;3:581-7.

103. Shokoohi M, Bauer GR, Kaida A, Lacombe-Duncan A, Kazemi M, Gagnier B, de Pokomandy A, Loutfy M. Social determinants of health and self-rated health status: a comparison between women with HIV and women without HIV from the general population in Canada. PLoS One. 2019;14:e0213901.

104. Santos V da F, Pedrosa SC, Aquino P de S, Lima ICV de, Cunha GH da, Galvão MTG. Social support of people with HIV/AIDS: the social determinants of health model. Rev Bras Enferm. 2018;71:625-30. 
105. Robillard A, Padi A, Lewis K, Julious C, Troutman J. Advice for prevention from HIV-positive African-American women: "my story is not just a story." Cult Health Sex. 2017;19:630-42.

106. Jones J, Sullivan PS, Sanchez TH, Guest JL, Hall EW, Luisi N, Zlotorzynska M, Wilde G, Bradley H, Siegler AJ. Similarities and differences in COVID-19 awareness, concern, and symptoms by race and ethnicity in the United States: Cross-Sectional Survey. J Med Internet Res. 2020;22:e20001.

107. Edelman EJ, Aoun-Barakat L, Villanueva M, Friedland G. Confronting another pandemic: lessons from HIV can inform our COVID-19 response. AIDS Behav. 2020;24:1977-9.

108. Chin-Hong P, Alexander KM, Haynes N, Albert MA. Pulling at the heart: COVID-19, race/ethnicity and ongoing disparities. Nat Rev Cardiol. 2020;17:533-5.

109. Pflugeisen BM, Mou J. Empiric evidence of ethnic disparities in coronavirus positivity in Washington State. Ethn Health. 2021;26:36-48.

110. Tan TQ, Kullar R, Swartz TH, Mathew TA, Piggott DA, Berthaud V. Location matters: geographic disparities and impact of coronavirus disease 2019 (COVID-19). J Infect Dis. 2020. https://doi.org/10.1093/infdis/jiaa583.
111. Geter A, Sutton MY, Hubbard McCree D. Social and structural determinants of HIV treatment and care among black women living with HIV infection: a systematic review: 2005-2016. AIDS Care. 2018;30:409-16.

112. Summers NA, Colasanti JA, Feaster DJ, Armstrong WS, Rodriguez A, Jain MK, Jacobs P, Metsch LR, Del Rio C. Predictors for poor linkage to care among hospitalized persons living with HIV and co-occurring substance use disorder. AIDS Res Hum Retroviruses. 2020;36:406-14.

113. Stopka TJ, Brinkley-Rubinstein L, Johnson K, Chan PA, Hutcheson M, Crosby R, Burke D, Mena L, Nunn A. HIV clustering in Mississippi: spatial epidemiological study to inform implementation science in the deep south. JMIR public Heal Surveill. 2018;4:e35.

Publisher's Note Springer Nature remains neutral with regard to jurisdictional claims in published maps and institutional affiliations. 